\title{
RE: Office-Based Kyphoplasty: A Viable Option Using Local Anesthesia and Oral Sedation
}

\section{TO THE EDITOR:}

Office-based kyphoplasty: A viable option using local anesthesia and oral sedation by Worts and Chandler (1) was a good article to read with valuable information. Office-based or daycare interventions are being popularized these days. The authors have reported almost no complications in such settings, which is promising and appreciable.

Patient selection is an important factor for better outcome in this regard. However, in the inclusion criteria for office-based procedures, American Society of Anesthesiologists (ASA) class $\leq 3$ was considered. ASA physical status 3 denotes a patient with severe systemic disease (2), which may add risk to the office-based procedures. Considering that the authors could keep the resuscitation equipments ready, emergencies could have been managed well if there were any. Considering that the hospitals were 10 minutes away, ASA class $\leq 2$ would have been a better choice.
Another query to the authors is whether the patients were subdivided into ASA classification, as this was not mentioned in the article or tables. We believe ASA classification is very important criteria for officebased interventions, with a backup resuscitation team and equipment.

These are the suggestions we want to make to the authors.

\author{
Samarjit Dey, MD \\ Department of Anaesthesiology \\ All India Institute of Medical Science \\ Raipur, Chhattisgarh, India \\ E-mail: drsamar0002@gmail.com \\ Jitendra Kalbande, MD \\ Department of Anaesthesiology \\ All India Institute of Medical Science \\ Raipur, Chhattisgarh, India
}

\section{REFERENCES}

1. Worts PR, Chandler III GS. Office-based kyphoplasty: A viable option using local anesthesia with oral sedation. Pain Physician 2019; 22:177-185.
2. Doyle DJ, Garmon EH. American Society of Anesthesiologists Classification (ASA Class). In: StatPearls [Internet]. Treasure Island (FL): StatPearls Publishing; 2019
Jan. Available from: www.ncbi.nlm.nih. gov/books/NBK441940. Accessed July 18, 2019. 